\title{
Inflation uncertainty and interest rates: is the Fisher relation universal?
}

\section{Hakan Berument , Nildag Basak Ceylan \& Hasan Olgun}

To cite this article: Hakan Berument, Nildag Basak Ceylan \& Hasan Olgun (2007) Inflation uncertainty and interest rates: is the Fisher relation universal?, Applied Economics, 39:1, 53-68, DOI: $10.1080 / 00036840500427908$

To link to this article: http://dx.doi.org/10.1080/00036840500427908

$$
\text { Published online: } 30 \text { Oct } 2009 .
$$

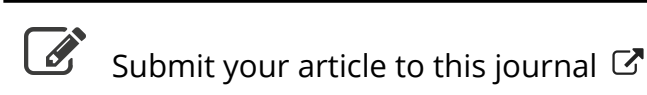

\footnotetext{
Щ Article views: 131
}

Q View related articles $₫$

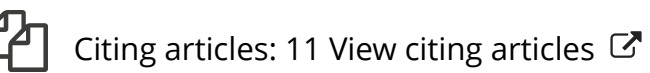




\title{
Inflation uncertainty and interest rates: is the Fisher relation universal?
}

\author{
Hakan Berument ${ }^{\mathrm{a}, *}$, Nildag Basak Ceylan ${ }^{\mathrm{b}}$ and Hasan Olgun ${ }^{\mathrm{c}}$ \\ ${ }^{a}$ Department of Economics, Bilkent University, 06800, Ankara, Turkey \\ ${ }^{\mathrm{b}}$ Department of Management, Atilim University, 06836, Ankara, Turkey \\ ${ }^{\mathrm{c}}$ Department of Economics, Baskent University, 06530, Ankara, Turkey
}

This paper tests the validity of the Fisher hypothesis, which establishes a positive relation between interest rates and expected inflation, for the G7 countries and 45 developing economies. For this purpose, we estimate a version of the GARCH specification of the hypothesis for all countries included in the sample. We also test the augmented Fisher relation by including the inflation uncertainty in the equation. The simple Fisher relation holds in all G7 countries but in only 23 developing countries. There is a positive and statistically significant relationship between interest rates and inflation uncertainty for six of the G7 and 18 of the developing countries and this relationship is negative for seven developing countries.

\section{Introduction}

The intricacies of the relationships among interest rates, (expected) inflation (economic performance) and inflation uncertainty (risk) have, since Fisher (1907), occupied the minds of the academicians and policymakers. One natural consequence of this concern has been, especially during the last few decades, the emergence of a highly specialized and sophisticated literature. Evaluating this literature is beyond the scope of this paper. In this paper we take a slightly different position from our predecessors and raise three simple but basic questions. First, is the simple Fisher hypothesis, which states that there is a positive relationship between (expected) inflation and interest rates universally valid? In particular, does it hold in all developing countries? Secondly, assuming that it does, in what manner? That is, does it hold in its weak or strong form? Thirdly, does inflation risk affect the interest rate in all countries?

One reason for raising the first question is that if the relation does not hold, then it does not make sense to talk about the Fisher hypothesis. Another reason is that there is no a priori reason to assume that the hypothesis holds in every country. For instance, Crowder and Hoffman (1996) note that 'Starting with Fisher and extending to the present (for example, Mishkin (1992) and Evans and Lewis (1995)) this seemingly simple and intuitive hypothesis has found little empirical support.' The reason for raising the second question is that even if the Fisher hypothesis holds for a particular country, then this fact is not sufficient to delineate the nature of the underlying transmission mechanism. A statistically significant and positive coefficient of (expected) inflation will imply a different effect on real interest rate depending on whether it is less than, equal to or greater than one.

The nature of the relation between interest rate and inflation uncertainty (risk) is of utmost importance from a theoretical point of view. Two divergent schools of thought have emerged on this issue. The adherents of the loanable funds theory, e.g. Juster and Wachel (1972a, b) and Juster and Taylor (1975) argue that if the variability of the nominal income is not equal to the variability of inflation, then the latter will affect the variability of

*Corresponding author. E-mail: berument@bilkent.edu.tr 
real income. Hence, consumer confidence will be affected. If consumers seek to protect themselves against inflation by raising their savings a positive relation between inflation uncertainty and saving will emerge. While Hahn (1970) constructs a theoretical model of this relation the above-mentioned authors provide empirical evidence for this positive relationship; that is they show that there is a negative relation between inflation uncertainty (risk) and interest rates. In contrast to the adherents of the loanable funds theory, those researchers who adopt Markowitz's (1952) portfolio theory maintain that risk-averse investors will seek compensation in the form of higher returns against risk simply because unanticipated inflation decreases the real return on the t-bill rate. Within this line of research, Fama (1975), Fama and Schwart (1977), Mishkin (1981), Fama and Gibbons (1982) and Chan (1994) provide empirical evidence on the positive relation between t-bill rate and inflation uncertainty. Comparing these two approaches and the related empirical findings it is fair to conclude that the relation between the interest rate and inflation risk cannot be established on a priori grounds. Hence, one safe line of research is to investigate this relation for as many and diverse economies as possible within a common theoretical framework.

Two technical issues have been frequently discussed in the literature: modelling inflation uncertainty and measuring expected inflation. In this paper we address these issues directly. We measure inflation uncertainty by the conditional variance of inflation and incorporate it into the simple Fisher equation. The expected inflation is the forecasted level of the next period's inflation given the specified inflation equation. The simple and risk augmented equations are estimated for the $\mathrm{G} 7$ and 45 developing countries.

This paper builds on the previous empirical research in several respects. First, to address the two basic questions raised above, we have decided to estimate the simple and risk augmented Fisher equation for as many countries as possible depending on data availability. Given that the Fisher relation has mostly been examined for advanced economies, we have enlarged the sample of developing economies to establish a ground for comparison. We hope that such a comparison will enable future researchers to formulate hypotheses on the relation between the Fisher hypothesis and the degree of sophistication of the financial markets. In this connection, we would like to emphasize that the empirical evidence for developed countries is far from being conclusive. For instance, according to Hsing (1997), a survey of the literature would indicate that empirical tests of the Fisher hypothesis are inconclusive. This opinion has also been expressed by Dutt and Ghosh (1995) who 'soundly reject' the hypothesis for Canada. Similarly, using quarterly data and vector autoregressive innovations Olekalns (1996) rejects the strong form of the hypothesis for Australia. In contrast to these refutations Lee et al. (1998) using Mishkin's (1992) monthly data pertaining to the 1979:10-1990:12 period find some evidence in favour of both longand short-run Fisher effect. However, compared to Mishkin's original results, they find less support for the long-run effect and somewhat more support for the short-run effect. They attribute these differences to methodological differences.

Secondly, studies that seek to test the long-run relation between interest rate and expected inflation have tended to use annual data. However, this may lead to aggregation bias as suggested by Rosanna and Seater (1995). Hence, in this paper we use monthly data. Thirdly, to the best of the authors' knowledge, excluding Berument and Jelassi (2002) who include 26 countries in their study, this study is the first to test the Fisher hypothesis for as many as 52 countries within a common framework. This is a novel aspect of the present paper. As noted by Hsing (1997) and Olekalns (1996), the inconclusiveness of the empirical tests is largely due to the differences in the methodologies and datasets employed. To avoid this pitfall here, we employ a common specification and identical dataset for the 52 countries included in the sample. Finally, we provide robustness tests for our specifications.

The evidence we provide in this paper casts doubts on the validity of the Fisher hypothesis. We show that out of a sample of 45 , the hypothesis does not hold for 22 developing countries. We also show that the Fisher hypothesis holds in its augmented form in 21 but does not hold in 24 developing countries.

The rest of the paper is organized as follows: Section II elaborates the measures of expected inflation and inflation uncertainty and shows how the latter can be incorporated into the simple Fisher equation. Section III presents and evaluates the estimation results. Section IV evaluates the results of the robustness tests. The final section summarizes the main findings.

\section{Expectations, Risk and GARCH Models}

Modelling inflation volatility is necessary because risk averse agents while making their decisions will give importance to both the anticipated level of macroeconomic variables and the assessed risk of the variable. 
There are many ways of measuring inflation uncertainty. Hafer (1986) and Davis and Kanago (1996) employ a survey based-approach and measure uncertainty by the standard deviation of inflation forecasts, whereas Johnson (2002) uses the absolute value of inflation forecast errors. In contrast, in the studies of Bomberger (1996) and Mankiw et al. (2003) survey results are not regarded as a good measure of inflation uncertainty. Bomberger (1996) claims that uncertainty cannot be measured by using the dispersion of the survey forecasts and that if forecasters try not to deviate from others' forecasts, this will lead to a bias in inflation. The findings of Mankiw et al. (2003) also do not support the usage of survey results. Another method to measure uncertainty is to use Kalman Filter. This method allows estimating the time varying parameters of an inflation specification. It captures the effects of uncertainty on the dynamics of the inflation process.

Finally, autoregressive conditional heteroskedasticity $(\mathrm{ARCH})$ or the generalized ARCH $(\mathrm{GARCH})$ processes can be used. These models can measure the uncertainty related to the inflation shocks by using the conditional variance of residuals. We believe this is a better way to measure inflation uncertainty (see Berument et al. (2005) for a detailed discussion). The next sub-section elaborates on the calculations of the expected inflation and inflation risk.

\section{Expected inflation and modelling inflation risk}

We assume that inflation, $\pi_{t}$, follows an autoregressive process of order $q$ where the lag order is suggested by the final prediction error criteria. ${ }^{1,2}$

$$
\pi_{t+1}=i_{0}+\sum_{j=1}^{q} i_{j} \pi_{t+1-j}+\varepsilon_{t+1}
$$

where, $\pi_{t+1}$ is the inflation at time $t+1, i_{j}$ is the coefficient of the $j$ th lag of inflation and $\varepsilon_{t}$ is the discrete time real valued stochastic process. Also $\varepsilon_{t}$ has general error distribution with zero mean and $h_{t}^{2}$ variance. $^{3}$

$$
\frac{\varepsilon_{t+1}}{\Omega_{t}} \sim\left(0, h_{t}^{2}\right)
$$

The conditional variance of the unanticipated inflation with a given information set at time $t$ is $h_{t}^{2}$ with mean zero. Here $\Omega_{t}$ specifies all the information available to the agents at time $t$. The given information at time $t$ together with the conditional expectation of the inflation is:

$$
E_{t}\left(\frac{\pi_{t+1}}{\Omega_{t}}\right)=i_{0}+\sum_{j=1}^{q} i_{j} \pi_{t+1-j}
$$

With the help of the model introduced by Engle (1982), it is possible to measure the conditional variance of inflation at time $t$, which can be used as a proxy for inflation risk. ARCH models suggest that the lagged values of the squared residual terms within the equation can explain the conditional variance of the residual term. The ARCH model can be written as:

$$
h_{t}^{2}=d_{0}+\sum_{j=1}^{p} d_{1 j} \varepsilon_{t+1-j}^{2}
$$

In his work Bollerslev (1986) has added the lagged values of the conditional variance to the $\mathrm{ARCH}$ model. Thus, the new model, which is called GARCH model, can be written as in Equation 5 .

$$
h_{t}^{2}=d_{0}+\sum_{j=1}^{p} d_{1 j} \varepsilon_{t+1-j}^{2}+\sum_{j=1}^{q} d_{2 j} h_{t-j}^{2}
$$

Bollerslev noted that, in order to provide sufficient conditions for non-negativity and non-explosiveness of the conditional variances, all the estimated coefficients should be positive. Moreover, the sum of all $d_{1 j}$ and $d_{2 j}$ should also be less than one. After trying various specifications of GARCH models, we have chosen the most appropriate specification for each country that satisfies a battery of robustness tests that will be discussed later in the text.

\section{Estimation}

According to Fisher (1907), the nominal rates, $r_{t}$, move in accordance with the expected inflation rate, $\pi_{t}^{e}$, as shown in Equation 6 below:

$$
r_{t}=c_{0}+c_{\pi} \pi_{t+1}^{e}+\eta_{t}
$$

\footnotetext{
${ }^{1}$ The final prediction error (FPE) criteria selects the optimal lag length such that residuals of the inflation equation are no longer autocorrelated. This is important because Jansen and Cosimona (1988) argue that ARCH-LM tests of autocorrelated residuals wrongly suggest the presence of an $\mathrm{ARCH}$ effect, even when there is no ARCH effect.

${ }^{2}$ Alternative specifications have also been used in modeling inflation. Berument (1999), for instance, adds real wages to the model, to conclude that they fail to explain the interest rates at a statistically significant level for the United Kingdom. In the present study, we disregard real wages, and we model the Fisher equation as an AR process. Grier and Perry (1998) and Berument and Dincer (2005) have also used this procedure.

${ }^{3}$ Assuming standardized normal distribution could be too restrictive to account for excess kurtosis. Therefore, we assume that residuals have generalized error distribution that is the general case of the standard normal distribution (see Hamilton, 1994, p. 668).
} 
Sheehan (1996) may object to this procedure. In his interesting paper, he rightly notes that including expected inflation as an independent variable suggests that expectations are adaptive and appear to be inconsistent with rational expectations. In Equation 6, the current period inflation rate, and hence the real interest rates are not known. Hence, risk-averse agents will demand additional returns to hold risky assets. If there exists a one-to-one relationship between interest rates and expected inflation, $c_{\pi}$ will be equal to one, that is, the Fisher relation will hold in its strong form. In the weak form, $c_{\pi}$ is positive but not equal to one. Tobin (1965) notes that if wealth is composed of money and capital only, and high inflation raises the opportunity cost of holding money, money demand will decrease and hence the marginal productivity of capital will decline along with the interest rate. Accordingly, he suggests $c_{\pi}$ to be positive and less than one for the weak form of the Fisher hypothesis. On the other hand, Darby (1975) notes that if the nominal interest rate is taxed, $c_{\pi}$ is greater than one.

According to Equation 6, nominal interest rates are affected by the expected inflation only. Here, we allow inflation risk also to affect nominal interest rates and modify Equation 6 to read:

$$
r_{t}=c_{0}+c_{\pi} \pi_{t+1}^{e}+c_{h} h_{t}^{2}+\eta_{t}
$$

In Equation 7, we assume that the residual term has a zero mean and constant variance. Here, we have to calculate the values of expected inflation $\left(\pi_{t}^{e}\right)$ and the inflation risk $\left(h_{t}^{2}\right)$. In this paper, we calculate the expected inflation as the expected value of Equation 1 and the conditional variance of Equation 5 with rolling regressions. ${ }^{4}$

\section{An Evaluation of the Empirical Results}

The data on inflation (logarithmic first difference of CPI) and interest rates (Treasury bill rates) are gathered from International Monetary FundInternational Financial Statistics CD-ROM. Note that CPI series are seasonally unadjusted. However, we included 11 monthly dummies to account for the seasonality. The time span of each dataset is reported in Table 1. Simply because data on taxes could not be obtained for all countries, t-bill rates are pre-tax rates.
Table 2 and Table 3 present the estimation results of the Fisher equation without inflation risk (Panel A) and with inflation risk (Panel B) for the G7 and 45 developing countries respectively.

The Fisher hypothesis asserts that there is a positive relation between the expected inflation and the interest rate (see Fama, 1975; Fama and Gibbons, 1982; and Mishkin, 1992). Our results in Table 2, Panel A confirm this hypothesis for the G7 countries. The coefficients of the expected inflation are positive, less than one and statistically significant at $1 \%$ level for all G7 countries. This is in conformity with the previous findings for the developed countries such as Canada, the UK and the USA. Note that a positive but less than one value of the estimated coefficient implies the Fisher hypothesis holds in its weak form and lends support to Tobin (1965). The coefficients of the inflation uncertainty (risk) are also positive, less than one and statistically significant. ${ }^{5}$ However, this coefficient is significant at only at the $10 \%$ level for the UK and at the 5\% level for Japan. For the remaining G7 countries, it is significant at the 1\% level. Positive and significant coefficients lend support to the portfolio approach.

Estimation results for the 45 developing economies are presented in Table 3. Panel A of Table 3 shows that the simple Fisher relation is not supported for 22 countries. The estimated coefficient of the expected inflations is negative but statistically significant for Egypt. Leaving aside this particular case, the estimated coefficient of the expected inflation is not statistically significant for Armenia, Albania, Bahrain, Bulgaria, Dominica, Ghana, Grenada, Kuwait, Lao People, Lithuania, Malawi, Namibia, Nepal, Sierra Leone, Solomon Islands, Sri Lanka, St Lucia, Swaziland, Uganda, Zambia and Zimbabwe. Moreover, it continues to remain insignificant when inflation uncertainty is added to the equation. Hence, we will not elaborate the relation between the interest rates and expected inflation in these countries in order to save space. Thus, in view of the results presented in Panel A, we conclude that the simple Fisher hypothesis holds in 23 countries. In these countries the coefficients of expected inflation are significant at the $1 \%$ or $5 \%$ levels, are positive and less than one. Hence, the hypothesis holds in its weak form.

When the inflation uncertainty variable is added the basic result is robust. The number of developing countries where the hypothesis holds in its augmented

\footnotetext{
${ }^{4}$ The reason for using rolling regression is that if we used the full data span to get the estimate, we would be implicitly assuming that agents know the inflation rates for the full sample to estimate $\pi_{t}$ each $t$, which is not true (see Berument $e t$ al., 2005 for details).

${ }^{5}$ The level of significance is at the $5 \%$ level, unless otherwise noted.
} 
Table 1. The beginning and end dates of the dataset

\begin{tabular}{|c|c|c|c|c|}
\hline & \multicolumn{2}{|l|}{ CPI } & \multicolumn{2}{|l|}{ T-bill } \\
\hline & Beg. date & End date & Beg. date & End date \\
\hline Armenia & 1992:12 & 2004:08 & 1995:09 & 2004:08 \\
\hline Albania & 1991:01 & 2004:08 & 1994:07 & 2004:07 \\
\hline Bahamas & 1972:07 & 2004:08 & 1971:04 & 2004:08 \\
\hline Bahrain & 1975:07 & 2001:09 & 1987:06 & 2004:05 \\
\hline Barbados & $1965: 10$ & 2004:04 & 1967:01 & 2004:07 \\
\hline Bolivia & $1957: 01$ & 2004:08 & 1994:01 & 2004:08 \\
\hline Brazil & 1979:12 & 2004:08 & 1995:01 & 2004:08 \\
\hline Bulgaria & 1991:01 & 2004:08 & 1992:01 & 2004:06 \\
\hline Canada & 1957:01 & 2004:08 & 1957:01 & 2004:08 \\
\hline China & 1980:10 & 2004:07 & 1994:01 & 2004:08 \\
\hline Dominica & 1979:11 & 2004:07 & 1980:01 & 2004:07 \\
\hline Egypt & 1957:01 & 2004:07 & 1997:01 & $2004: 05$ \\
\hline Fiji & $1968: 12$ & 2004:06 & 1975:01 & 2004:06 \\
\hline France & 1957:01 & 2004:08 & 1970:01 & 2002:09 \\
\hline Germany & 1960:01 & 2004:08 & 1975:07 & 2004:08 \\
\hline Ghana & 1963:03 & 2004:04 & 1978:01 & 2004:06 \\
\hline Greece & 1957:01 & 2004:08 & 1983:01 & 2004:08 \\
\hline Grenada & 1976:01 & 2002:12 & 1980:01 & 2004:06 \\
\hline Hungary & 1976:01 & 2004:08 & 1988:12 & 2004:08 \\
\hline Iceland & 1983:01 & 2004:08 & 1984:01 & 2004:04 \\
\hline Israel & 1957:01 & 2004:08 & 1984:06 & 2004:07 \\
\hline Italy & 1957:01 & 2004:07 & $1977: 03$ & 2004:08 \\
\hline Jamaica & 1957:01 & 2004:08 & 1961:05 & 2004:08 \\
\hline Japan & 1957:01 & 2004:07 & 1957:01 & 2004:06 \\
\hline Kazakhstan & 1992:12 & 2004:08 & 1994:04 & 2004:08 \\
\hline Kenya & 1968:01 & 2004:06 & 1972:01 & 2004:07 \\
\hline Kuwait & 1973:01 & 2003:12 & 1979:04 & 2004:07 \\
\hline Lao People & 1993:05 & 2004:05 & 1994:12 & 2004:05 \\
\hline Lithuania & 1992:05 & 2004:08 & 1994:07 & 2004:08 \\
\hline Malawi & 1980:01 & 2004:01 & 1983:01 & 2004:07 \\
\hline Malaysia & 1957:01 & 2004:08 & 1976:01 & 2004:07 \\
\hline Malta & 1957:01 & 2004:05 & $1987: 11$ & 2003:09 \\
\hline Namibia & 1991:01 & 2004:05 & 1991:09 & 2004:07 \\
\hline Nepal & 1963:07 & 2004:07 & 1981:01 & 2004:07 \\
\hline Pakistan & 1957:01 & 2004:08 & 1991:03 & 2004:08 \\
\hline Philippines & 1957:01 & 2004:08 & 1976:01 & 2004:08 \\
\hline Romania & 1990:10 & 2004:07 & 1994:03 & 2003:05 \\
\hline Russia & 1992:01 & 2004:06 & 1995:01 & 2004:08 \\
\hline Sierra Leone & 1986:10 & 2004:06 & 1965:11 & 2004:07 \\
\hline Singapore & 1961:01 & 2004:07 & 1973:04 & 2004:08 \\
\hline Solomon Islands & 1978:01 & 2004:03 & 1981:03 & 2004:05 \\
\hline South Africa & 1957:01 & 2004:07 & 1957:01 & 2004:08 \\
\hline Sri Lanka & 1957:01 & 2004:08 & 1981:04 & 2004:06 \\
\hline St Lucia & 1964:04 & 2004:06 & 1980:01 & 2004:07 \\
\hline Swaziland & 1967:01 & 2004:07 & 1981:12 & 2004:08 \\
\hline Switzerland & $1957: 01$ & 2004:08 & 1980:01 & 2004:08 \\
\hline Turkey & 1969:01 & 2004:08 & 1985:09 & 2004:07 \\
\hline Uganda & 1981:04 & 2004:06 & 1980:01 & 2004:08 \\
\hline United Kingdom & 1957:01 & 2004:08 & 1964:01 & 2004:07 \\
\hline United States & 1957:01 & 2004:08 & 1964:01 & 2004:08 \\
\hline Zambia & 1985:01 & 2002:12 & 1978:01 & 2004:07 \\
\hline Zimbabwe & 1978:01 & 2002:02 & 1979:01 & 2004:08 \\
\hline
\end{tabular}

Note: Due to the availability of data in Japan we have used lending rate instead of Treasury bill rate. 
Table 2. Interest rate-inflation-inflation risk relationship (G7 countries)

\begin{tabular}{|c|c|c|c|c|c|}
\hline & \multicolumn{2}{|c|}{ Panel A: Fisher equation } & \multicolumn{3}{|c|}{ Panel B: Fisher equation with risk } \\
\hline & Constant & $\pi_{t+1}^{e}$ & Constant & $\pi_{t+1}^{e}$ & $h_{t}^{2}$ \\
\hline Canada & $5.657 * * *(27.63)$ & $0.397 * * * \quad(9.83)$ & $5.122 * * *(19.71)$ & $0.399 * * *(10.03)$ & $0.042 * * *(3.26)$ \\
\hline France & $5.659 * * *(27.63)$ & $0.489 * * *(16.38)$ & $4.519 * * * \quad(9.83)$ & $0.442 * * *(13.33)$ & $0.150 * * *(2.75)$ \\
\hline Germany & $4.457 * * *(35.98)$ & $0.259 * * * \quad(7.58)$ & $4.016 * * *(24.77)$ & $0.250 * * * \quad(7.36)$ & $0.050 * * *(3.76)$ \\
\hline Italy & $4.857 * * *(13.31)$ & $0.939 * * *(18.49)$ & $4.262 * * *(11.05)$ & $0.822 * * *(15.90)$ & $0.161 * * *(4.52)$ \\
\hline Japan & $4.054 * * *(32.09)$ & $0.082 * * * \quad(2.93)$ & $1.572 \quad(1.610)$ & $0.071 * * * \quad(2.92)$ & $0.148 * * \quad(2.46)$ \\
\hline United Kingdom & $6.393 * * *(31.21)$ & $0.219 * * * \quad(6.17)$ & $5.298 * * * \quad(8.28)$ & $0.216 * * * \quad(6.30)$ & $0.101 * \quad(1.82)$ \\
\hline United States & $4.075 * * *(20.40)$ & $0.446 * * *(11.64)$ & $3.508 * * *(15.53)$ & $0.448 * * *(11.87)$ & $0.090 * * *(3.12)$ \\
\hline
\end{tabular}

Note: $t$-statistics are given in parentheses and $* * *, * *$ and $*$ indicate the level of significance at $1 \%, 5 \%$ and $10 \%$ levels respectively.

form is 21. Finally, we note that among these countries, the coefficient of the inflation risk is positive and significant, in seven countries negative and statistically significant coefficients are observed.

Our basic conclusion that the Fisher hypothesis does not hold in a considerable number of developing economies requires an explanation. Here, we can only offer a few tentative explanations. First, the hypothesis implicitly assumes that nominal interest rates freely adjust to changes in the actual or expected inflation. Obviously, this will not be the case if the interest rates are suppressed, as was the case in Turkey in 1978. Secondly, even if the interest rates are not suppressed, they will not or will only partially respond to the changes in inflation in those countries where the money markets are not sufficiently sophisticated. Finally, the adjustment of the interest rates will be hampered in those countries where they are considered to be a 'sin' for cultural reasons.

The validity of the above conclusions depends on the appropriateness of the GARCH specification. Accordingly, in the following section, we perform a series of robustness tests.

\section{Robustness Tests}

In this section we provide a battery of robustness tests for our estimates similar to Engle (1982). We first perform the ARCH-LM tests for the inflation equation (Equation 1) to motivate the time varying variability of inflation uncertainty. In order to perform the test, the inflation equation is estimated first by regressing inflation on a constant term with monthly dummies and its appropriate lags. Then squared residuals of the inflation equation are regressed on its $3,6,9,12,18,24,30$ and 36 lags for the full sample period. ${ }^{6}$ Their $p$-values are reported in Table 4 for all countries. It is clear that for each country we reject the null hypothesis of no heteroskedasticity for various lags. Thus, we can model inflation with a time varying inflation variance model.

The second column of Table 5 reports the GARCH specification. The sufficient condition for the nonnegativity of the conditional variance is that its coefficient be positive. Moreover, to satisfy the nonexplosiveness of conditional variance the sum of the slope coefficients (sum of all coefficients excluding the intercept term) in the conditional variance should be less than one. The third column reports the intercept term $\left(d_{0}\right)$ and the fourth column reports the sum of the slope terms when the GARCH specification is estimated for the full sample period. ${ }^{7}$ We note that intercept term is always positive and the sum of slope terms is always less than one. Therefore, the non-negativity and non-explosiveness requirement of the conditional variances are satisfied. In order to save space, we do not report the individual coefficients of the GARCH specifications but they were all positive.

Next we perform non-parametric sign and size bias test for the standardized residuals $\left(\varepsilon_{t+1} / h_{t}\right)$. We report the estimations of the test statistics of sign bias test, negative size bias test, positive size bias test and joint

\footnotetext{
${ }^{6}$ Some of the countries had outliers in the inflation series. This could alter the results (for example, see Tolvi 1999 and 2000). Thus for Bahamas, Bahrain, Brazil, Bulgaria, Germany, Greece, Kuwait, Lithuania, Malawi, Philippines, Sierra Leone, Turkey, Zambia and Zimbabwe, we perform the ARCH-LM test after accounting for these outliers.

${ }^{7}$ Note that when we calculate the expected inflation and conditional variance with rolling regression, reporting the robustness test for all the estimates will be too tedious and costly.
} 


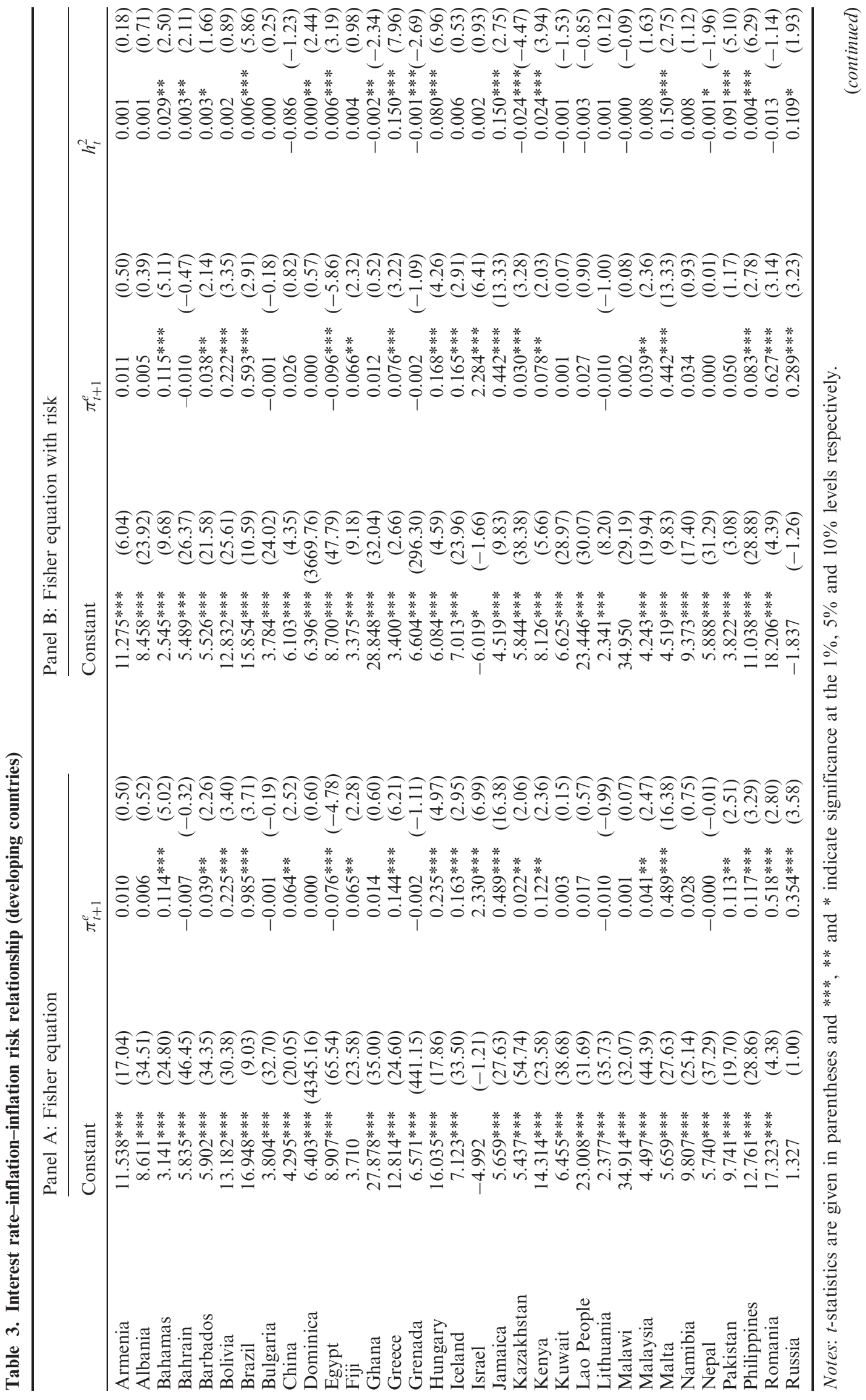




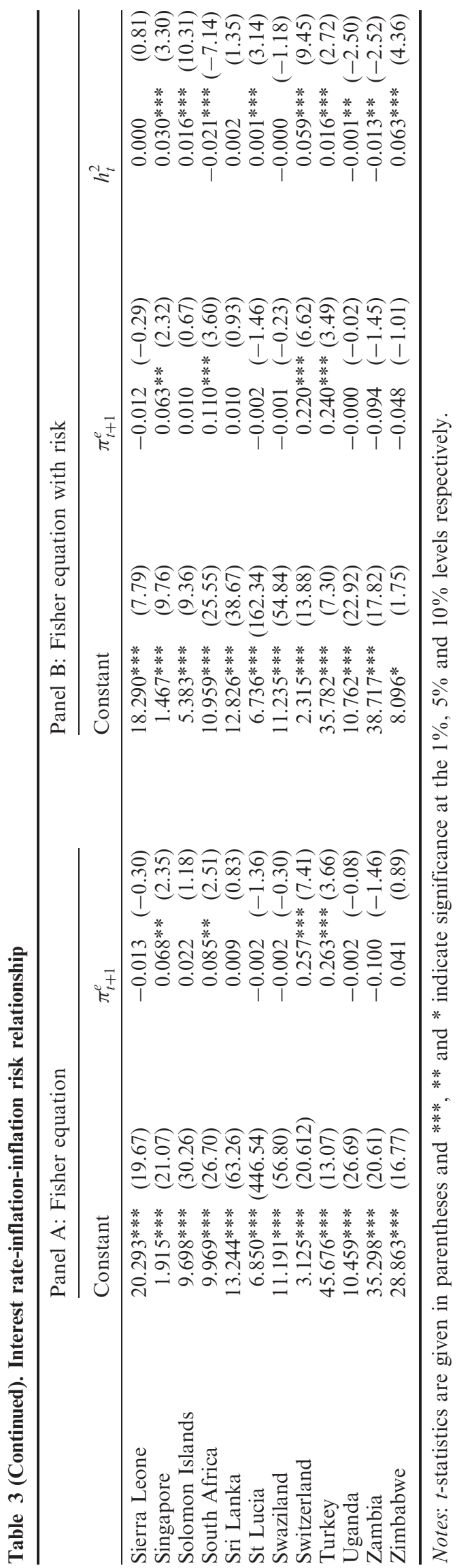




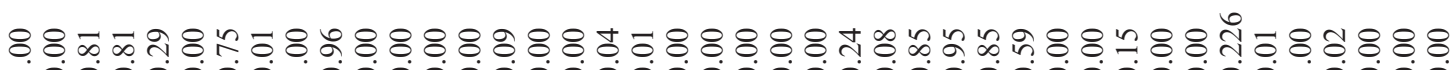
$-0000000-0000000000000000000000000000-0000$

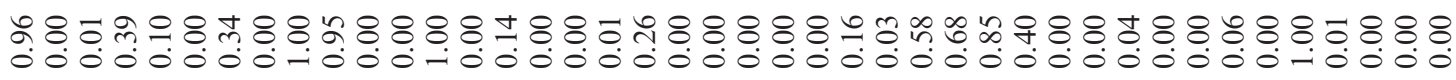

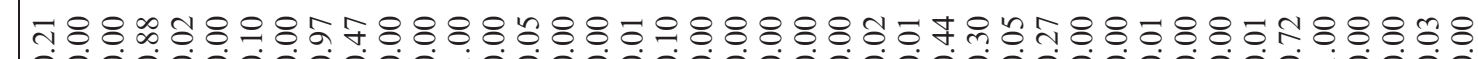

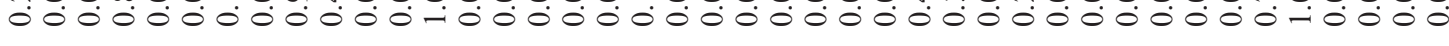

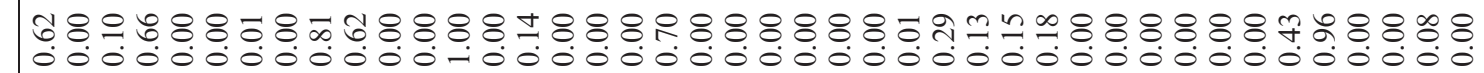

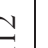

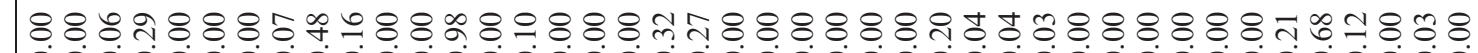
000000000000000000000000000000000000000000

8.

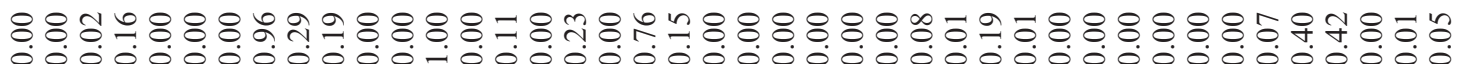

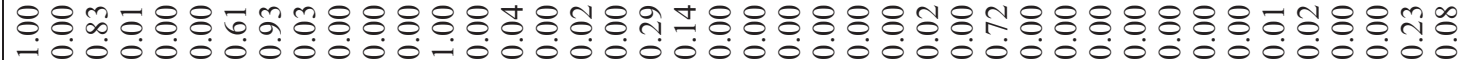




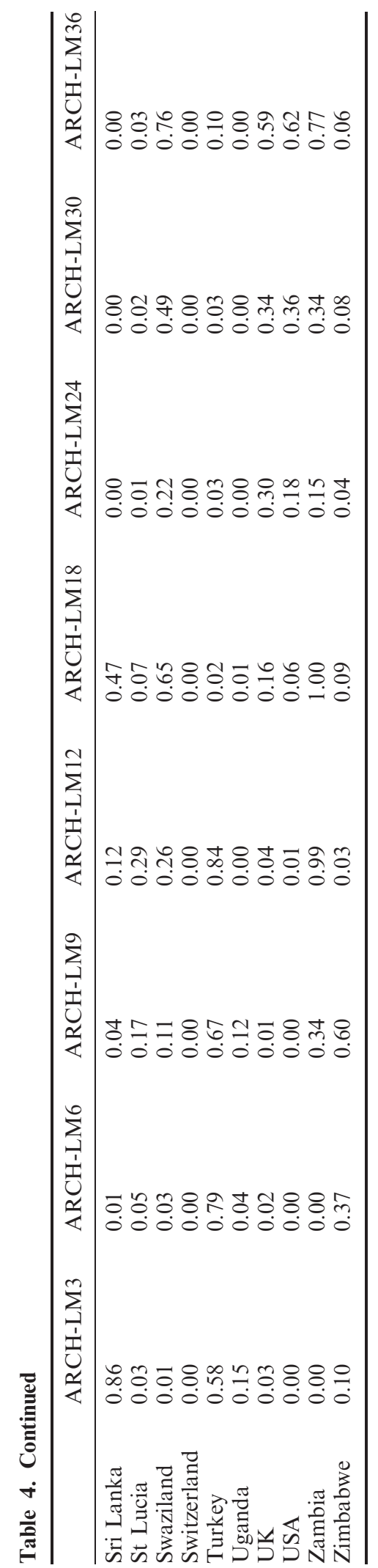


Table 5. Robustness test of GARCH specification

\begin{tabular}{|c|c|c|c|c|c|c|c|}
\hline & \multicolumn{3}{|l|}{ Panel A: } & \multicolumn{4}{|c|}{ Panel B: Non-parametric tests } \\
\hline & Specification & $\mathrm{d}_{0}$ & $\mathrm{~d}_{1}+\mathrm{d}_{2}$ & Sign bias & Negative size & Positive size & Joint test \\
\hline Albania & GARCH $(1,1)$ & 0.20 & 0.75 & 0.17 & 0.95 & 0.64 & 0.24 \\
\hline Armenia & $\operatorname{GARCH}(3,1)$ & 52.30 & 0.28 & 0.17 & 0.91 & 0.63 & 0.23 \\
\hline Bahamas & GARCH $(1,1)$ & 23.35 & 0.01 & 0.26 & 0.54 & 0.88 & 0.70 \\
\hline Bahrain & GARCH $(1,1)$ & 94.50 & 0.49 & 0.35 & 0.12 & 0.76 & 0.47 \\
\hline Barbados & GARCH $(1,1)$ & 2.45 & 0.99 & 0.26 & 0.17 & 0.47 & 0.49 \\
\hline Bolivia & $\operatorname{GARCH}(2,1)$ & 45.65 & 0.83 & 0.24 & 0.98 & 0.66 & 0.68 \\
\hline Brazil & GARCH $(1,2)$ & 2263.22 & 0.96 & 0.42 & 0.97 & 0.41 & 0.40 \\
\hline Bulgaria & $\operatorname{GARCH}(3,2)$ & 32933.93 & 0.42 & 0.23 & 1.00 & 0.78 & 0.49 \\
\hline Canada & GARCH $(1,1)$ & 2.07 & 0.84 & 0.89 & 0.42 & 0.59 & 0.63 \\
\hline China & GARCH $(1,1)$ & 14.82 & 0.07 & 0.39 & 0.56 & 0.46 & 0.82 \\
\hline Dominica & $\operatorname{GARCH}(3,1)$ & 65.67 & 0.80 & 0.62 & 0.81 & 0.50 & 0.87 \\
\hline Egypt & $\operatorname{GARCH}(1,1)$ & 34.77 & 0.95 & 0.36 & 0.75 & 0.84 & 0.60 \\
\hline Fiji & GARCH $(1,1)$ & 8.33 & 0.88 & 0.42 & 0.70 & 0.54 & 0.86 \\
\hline France & GARCH $(1,1)$ & 2.77 & 0.63 & 0.09 & 0.90 & 0.57 & 0.30 \\
\hline Germany & $\operatorname{GARCH}(1,1)$ & 0.25 & 0.90 & 0.78 & 0.21 & 0.98 & 0.57 \\
\hline Ghana & GARCH $(1,1)$ & 17.89 & 0.98 & 0.68 & 0.66 & 0.50 & 0.89 \\
\hline Greece & $\operatorname{GARCH}(1,1)$ & 38.88 & 0.47 & 0.42 & 0.63 & 0.80 & 0.50 \\
\hline Grenada & $\operatorname{GARCH}(1,1)$ & 18.18 & 0.80 & 0.28 & 0.68 & 0.49 & 0.75 \\
\hline Hungary & $\operatorname{GARCH}(1,1)$ & 149.90 & 0.14 & 0.31 & 0.89 & 0.74 & 0.34 \\
\hline Iceland & $\operatorname{GARCH}(2,1)$ & 0.01 & 0.99 & 0.54 & 0.74 & 0.60 & 0.77 \\
\hline Israel & GARCH $(1,2)$ & 9.33 & 0.89 & 0.41 & 0.648 & 0.92 & 0.69 \\
\hline Italy & $\operatorname{GARCH}(1,2)$ & 0.41 & 0.97 & 0.96 & 0.42 & 0.96 & 0.78 \\
\hline Jamaica & $\operatorname{GARCH}(1,1)$ & 2.77 & 0.63 & 0.09 & 0.90 & 0.57 & 0.30 \\
\hline Japan & $\operatorname{GARCH}(2,1)$ & 8.71 & 0.53 & 0.21 & 0.76 & 0.98 & 0.34 \\
\hline Kazakhstan & GARCH $(1,1)$ & 7.95 & 0.90 & 0.33 & 0.88 & 0.42 & 0.68 \\
\hline Kenya & $\operatorname{GARCH}(1,1)$ & 22.06 & 0.93 & 0.99 & 0.37 & 0.82 & 0.78 \\
\hline Kuwait & GARCH $(1,1)$ & 73.15 & 0.29 & 0.35 & 0.82 & 0.99 & 0.77 \\
\hline Lao People & $\operatorname{GARCH}(1,3)$ & 111.77 & 0.72 & 0.99 & 0.36 & 0.59 & 0.75 \\
\hline Lithuania & $\operatorname{GARCH}(3,3)$ & 27.61 & 0.68 & 0.74 & 0.59 & 0.73 & 0.81 \\
\hline Malawi & GARCH $(1,1)$ & 453.10 & 0.73 & 0.33 & 0.42 & 0.88 & 0.77 \\
\hline Malaysia & GARCH $(1,2)$ & 2.37 & 0.98 & 0.94 & 0.53 & 0.81 & 0.79 \\
\hline Malta & $\operatorname{GARCH}(1,1)$ & 2.43 & 0.67 & 0.10 & 0.91 & 0.52 & 0.33 \\
\hline Namibia & GARCH $(1,1)$ & 28.81 & 0.55 & 0.98 & 0.71 & 0.80 & 0.98 \\
\hline Nepal & $\operatorname{GARCH}(1,1)$ & 26.95 & 0.93 & 0.25 & 0.97 & 0.83 & 0.46 \\
\hline Pakistan & $\operatorname{GARCH}(1,1)$ & 4.78 & 0.97 & 0.60 & 0.28 & 0.06 & 0.12 \\
\hline Philippines & $\operatorname{GARCH}(3,1)$ & 19.55 & 0.89 & 0.46 & 0.75 & 0.40 & 0.46 \\
\hline Romania & GARCH $(1,1)$ & 151.75 & 0.90 & 0.66 & 0.36 & 0.65 & 0.44 \\
\hline Russia & GARCH $(1,1)$ & 19.08 & 0.50 & 0.41 & 1.00 & 0.53 & 0.71 \\
\hline Sierra Leone & $\operatorname{GARCH}(2,1)$ & 157.35 & 0.74 & 0.80 & 0.64 & 0.94 & 0.61 \\
\hline Singapore & GARCH $(1,1)$ & 5.06 & 0.80 & 0.20 & 0.55 & 0.76 & 0.16 \\
\hline S. Islands & GARCH $(1,1)$ & 19.29 & 0.95 & 0.74 & 0.24 & 0.82 & 0.68 \\
\hline S. Africa & $\operatorname{GARCH}(2,1)$ & 0.70 & 0.99 & 0.22 & 0.26 & 0.96 & 0.59 \\
\hline Sri Lanka & $\operatorname{GARCH}(1,1)$ & 21.92 & 0.89 & 0.17 & 0.26 & 0.90 & 0.47 \\
\hline St Lucia & $\operatorname{GARCH}(1,1)$ & 73.15 & 0.52 & 0.89 & 0.63 & 0.94 & 0.96 \\
\hline Swaziland & $\operatorname{GARCH}(1,3)$ & 199.20 & 0.76 & 0.24 & 0.98 & 0.45 & 0.66 \\
\hline Switzerland & $\operatorname{GARCH}(1,1)$ & 1.43 & 0.90 & 0.80 & 0.27 & 0.63 & 0.55 \\
\hline Turkey & $\operatorname{GARCH}(1,1)$ & 255.37 & 0.65 & 0.19 & 0.89 & 0.66 & 0.39 \\
\hline Uganda & GARCH $(1,1)$ & 383.88 & 0.94 & 0.49 & 0.90 & 0.89 & 0.81 \\
\hline $\mathrm{UK}$ & $\operatorname{GARCH}(1,1)$ & 6.97 & 0.79 & 0.24 & 0.97 & 0.32 & 0.14 \\
\hline USA & $\operatorname{GARCH}(1,1)$ & 0.56 & 0.92 & 0.65 & 0.32 & 0.92 & 0.80 \\
\hline Zambia & GARCH(2,2) & 1814.20 & 0.57 & 0.69 & 0.99 & 0.82 & 0.96 \\
\hline Zimbabwe & $\operatorname{GARCH}(1,1)$ & 64.83 & 0.79 & 0.38 & 0.86 & 0.99 & 0.80 \\
\hline
\end{tabular}

Note: $* * *$ and $* * *$ denote significance levels at $1 \%, 5 \%$ and $10 \%$ respectively.

test in Panel B of Table 5. While making the calculation of the test statistics, we standardized the residuals by dividing the estimated residuals by conditional standard errors $\left(e_{t} / h_{t}\right)$. Later on we have added two dummy variables as $m(t)$ and $p(t)$ such that, $m(t)=1$ if the normalized residual is negative, 0 otherwise and $p(t)=1$ if it is positive and 0 otherwise. Two interactive dummy variables 
Table 6. Ljung-Box $Q$ statistics

\begin{tabular}{|c|c|c|c|c|c|c|c|c|}
\hline & JB3 & JB6 & JB9 & JB12 & JB18 & JB24 & JB30 & JB36 \\
\hline Albania & 0.88 & 0.68 & 0.43 & 0.60 & 0.44 & 0.06 & 0.06 & 0.06 \\
\hline Armenia & 0.76 & 0.91 & 0.98 & 0.95 & 0.73 & 0.76 & 0.76 & 0.49 \\
\hline Bahamas & 0.99 & 1.00 & 1.00 & 1.00 & 1.00 & 0.98 & 0.89 & 0.71 \\
\hline Bahrain & 0.45 & 0.78 & 0.76 & 0.90 & 0.96 & 0.89 & 0.82 & 0.87 \\
\hline Barbados & 0.67 & 0.94 & 0.72 & 0.45 & 0.48 & 0.71 & 0.82 & 0.80 \\
\hline Bolivia & 0.89 & 0.99 & 1.00 & 1.00 & 1.00 & 1.00 & 1.00 & 1.00 \\
\hline Brazil & 0.51 & 0.87 & 0.96 & 0.99 & 0.99 & 0.99 & 1.00 & 1.00 \\
\hline Bulgaria & 0.98 & 0.92 & 0.98 & 0.95 & 0.99 & 0.99 & 1.00 & 1.00 \\
\hline Canada & 0.88 & 0.98 & 0.99 & 1.00 & 0.83 & 0.51 & 0.66 & 0.79 \\
\hline China & 0.86 & 0.77 & 0.86 & 0.11 & 0.16 & 0.02 & 0.02 & 0.01 \\
\hline Dominica & 0.97 & 0.98 & 0.72 & 0.81 & 0.40 & 0.41 & 0.41 & 0.18 \\
\hline Egypt & 0.70 & 0.94 & 0.80 & 0.73 & 0.86 & 0.48 & 0.50 & 0.39 \\
\hline Fiji & 0.75 & 0.78 & 0.59 & 0.40 & 0.56 & 0.52 & 0.32 & 0.29 \\
\hline France & 0.68 & 0.88 & 0.82 & 0.91 & 0.91 & 0.92 & 0.98 & 0.98 \\
\hline Germany & 0.49 & 0.66 & 0.83 & 0.95 & 0.96 & 0.36 & 0.20 & 0.00 \\
\hline Ghana & 0.98 & 0.83 & 0.93 & 0.96 & 0.87 & 0.81 & 0.83 & 0.77 \\
\hline Greece & 0.73 & 0.92 & 0.97 & 0.98 & 0.94 & 0.66 & 0.84 & 0.90 \\
\hline Grenada & 0.69 & 0.25 & 0.35 & 0.42 & 0.48 & 0.47 & 0.32 & 0.31 \\
\hline Hungary & 0.90 & 0.97 & 1.00 & 1.00 & 0.93 & 0.89 & 0.56 & 0.52 \\
\hline Iceland & 0.82 & 0.98 & 0.99 & 0.98 & 0.82 & 0.82 & 0.87 & 0.84 \\
\hline Israel & 0.19 & 0.33 & 0.35 & 0.12 & 0.16 & 0.10 & 0.07 & 0.00 \\
\hline Italy & 0.718 & 0.889 & 0.796 & 0.921 & 0.974 & 0.981 & 0.961 & 0.893 \\
\hline Jamaica & 0.68 & 0.88 & 0.82 & 0.91 & 0.91 & 0.92 & 0.98 & 0.98 \\
\hline Japan & 0.99 & 1.00 & 1.00 & 1.00 & 1.00 & 1.00 & 1.00 & 0.99 \\
\hline Kazakhstan & 0.85 & 0.79 & 0.76 & 0.23 & 0.57 & 0.73 & 0.86 & 0.72 \\
\hline Kenya & 0.69 & 0.87 & 0.97 & 0.92 & 0.95 & 0.90 & 0.63 & 0.69 \\
\hline Kuwait & 0.96 & 0.98 & 1.00 & 0.80 & 0.94 & 0.99 & 0.99 & 1.00 \\
\hline Lao People & 0.25 & 0.55 & 0.84 & 0.78 & 0.73 & 0.68 & 0.58 & 0.36 \\
\hline Lithuania & 0.62 & 0.43 & 0.48 & 0.22 & 0.12 & 0.08 & 0.00 & 0.00 \\
\hline Malawi & 0.91 & 0.61 & 0.87 & 0.69 & 0.34 & 0.46 & 0.48 & 0.05 \\
\hline Malaysia & 0.94 & 0.99 & 0.99 & 1.00 & 0.91 & 0.90 & 0.96 & 0.95 \\
\hline Malta & 0.72 & 0.92 & 0.86 & 0.91 & 0.90 & 0.91 & 0.97 & 0.98 \\
\hline Namibia & 0.52 & 0.13 & 0.25 & 0.06 & 0.09 & 0.02 & 0.00 & 0.00 \\
\hline Nepal & 0.57 & 0.76 & 0.89 & 0.87 & 0.20 & 0.08 & 0.20 & 0.23 \\
\hline Pakistan & 0.79 & 0.98 & 0.99 & 0.95 & 0.89 & 0.66 & 0.82 & 0.77 \\
\hline Philippines & 0.68 & 0.75 & 0.59 & 0.43 & 0.09 & 0.16 & 0.10 & 0.07 \\
\hline Romania & 0.40 & 0.54 & 0.36 & 0.46 & 0.55 & 0.31 & 0.18 & 0.12 \\
\hline Russia & 0.32 & 0.65 & 0.88 & 0.95 & 0.99 & 1.00 & 1.00 & 1.00 \\
\hline Sierra Leone & 0.83 & 0.98 & 1.00 & 0.83 & 0.86 & 0.07 & 0.05 & 0.00 \\
\hline Singapore & 0.93 & 0.98 & 0.98 & 0.97 & 0.94 & 0.47 & 0.56 & 0.14 \\
\hline S. Islands & 0.92 & 0.55 & 0.57 & 0.61 & 0.36 & 0.25 & 0.10 & 0.12 \\
\hline S. Africa & 1.00 & 0.95 & 0.97 & 0.99 & 1.00 & 0.99 & 0.98 & 0.98 \\
\hline Sri Lanka & 0.91 & 0.99 & 0.98 & 0.97 & 0.99 & 0.01 & 0.01 & 0.01 \\
\hline St Lucia & 0.95 & 0.94 & 0.86 & 0.80 & 0.56 & 0.13 & 0.07 & 0.08 \\
\hline Swaziland & 0.35 & 0.74 & 0.89 & 0.97 & 0.90 & 0.41 & 0.48 & 0.64 \\
\hline Switzerland & 0.93 & 1.00 & 1.00 & 1.00 & 1.00 & 0.98 & 0.95 & 0.92 \\
\hline Turkey & 0.64 & 0.51 & 0.69 & 0.49 & 0.20 & 0.26 & 0.31 & 0.40 \\
\hline Uganda & 0.40 & 0.31 & 0.17 & 0.31 & 0.48 & 0.66 & 0.76 & 0.53 \\
\hline UK & 0.57 & 0.57 & 0.82 & 0.79 & 0.76 & 0.29 & 0.49 & 0.30 \\
\hline USA & 0.61 & 0.84 & 0.79 & 0.88 & 0.73 & 0.31 & 0.08 & 0.06 \\
\hline Zambia & 0.99 & 0.83 & 0.87 & 0.52 & 0.35 & 0.02 & 0.00 & 0.00 \\
\hline Zimbabwe & 0.58 & 0.90 & 0.97 & 0.88 & 0.98 & 0.99 & 0.89 & 0.75 \\
\hline
\end{tabular}

are defined to be $\operatorname{sm}(t)=p(t) \cdot e(t) / h(t)$ and $\operatorname{sp}(t)=p(t) \cdot e(t) / h(t)$. Next we regressed $e(t) / h(t)$ on the constant term, $\mathrm{m}, \mathrm{sm}$ and $\mathrm{sp}$. In sign test, we tested if the coefficient of $\mathrm{m}$ is zero, for the negative sign test, we tested if the coefficient of sm is zero, for the positive sign test, we tested if the coefficient of $\mathrm{sp}$ is zero, and for the joint test the null hypotheses are jointly tested. Panel B reports the $p$-values of these test statistics. We observe that none of the $p$-values is significant at less than the $5 \%$ level and only two of 
†े

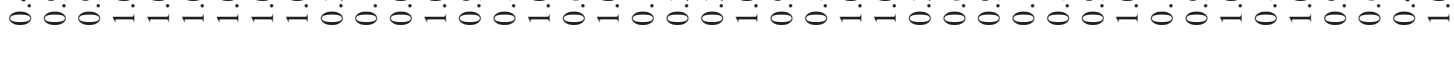
ऊँ⿱

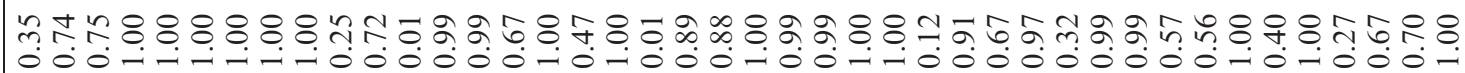

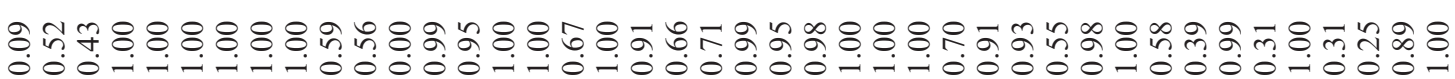
던

8뉴. $0000-1-100000-10-100000-0-1000000000-1000$

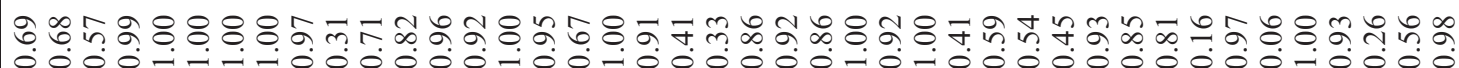
$0000-1-000000-00-000000-0-0000000000-0000$

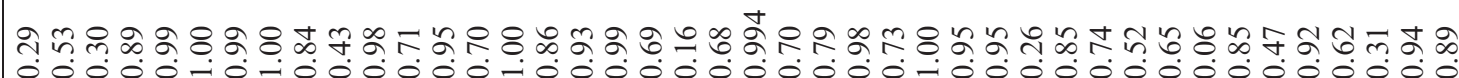

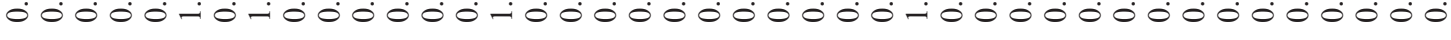

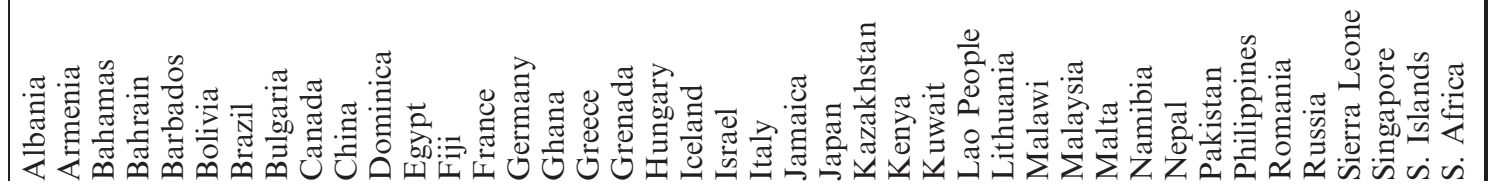




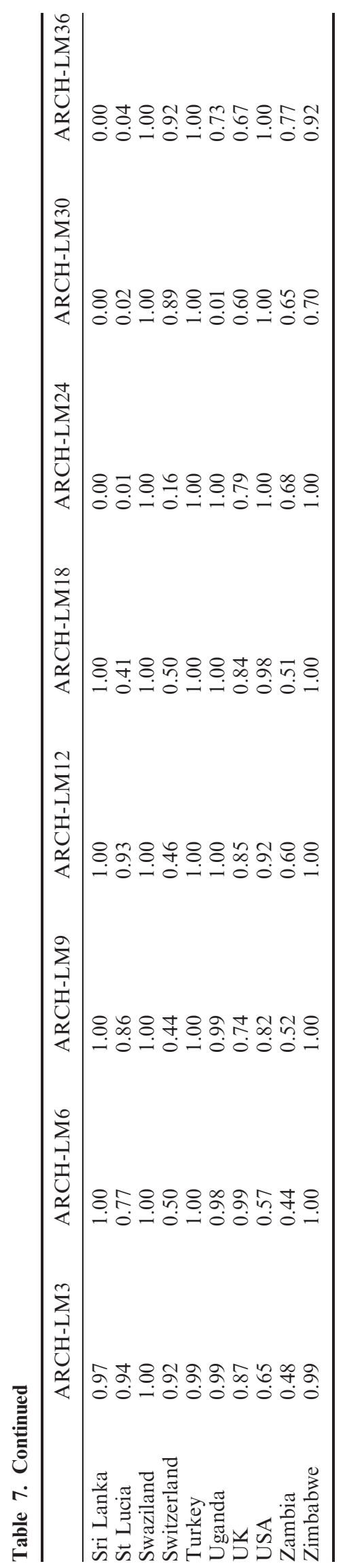


the countries' sign bias test is below $10 \%$. Thus, we can safely claim that non-parametric tests cannot reject our GARCH specifications.

Table 6 reports the $p$-values of the Ljung-Box $Q$ statistics for the standardized residuals for various lags. None of the $Q$ statistics are significant for the 3 , 6, 9 lags. For 12 lags, only Namibia is significant at $6 \%$. Even though the $p$-values become less than $5 \%$ for extended lags for some countries, we can safely disregard them. Hence we conclude that we cannot reject the null hypothesis of normal distribution for 39 countries at the $5 \%$ level for $3,6,9,12,18,24,30$ and 36 lags. Moreover, for 13 countries we cannot reject the null hypothesis of normal distribution depending on the lags chosen.

Next, we elaborate the ARCH-LM test for 3, 6, 9, 12, 18, 24, 30 and 36 lags in Table 7. In particular, we regress the squared standardized residuals on a constant term for 3, 6, 9, 12, 18, 24, 30 and 36 lags. We test if these lag terms are jointly statistically significant or not. The $p$-values reported in Table 7 cannot reject the null hypothesis of no ARCH effect for all countries except Albania at 9 lags, and Albania and Egypt at 12 lags. There are also some higher order lags, which are significant for some other countries but these are not many.

\section{Conclusion}

This paper aimed at investigating the relationship between the interest rates, expected inflation and inflation uncertainty (risk) in the G7 countries and as many developing economies as permitted by data availability. For tractability we have decided to test both the simple and augmented versions of the Fisher hypothesis by employing GARCH specification. Our findings show that the Fisher hypothesis holds in all G7 countries both in its simple and augmented versions. In these countries it holds in its weak form and the coefficient of the inflation risk is invariably positive, lending support to the portfolio approach to inflation uncertainty. In sharp contrast, the hypothesis fails to hold in more than half of the developing economies included in the sample.

We have reached two additional conclusions. In those developing economies where the Fisher hypothesis holds in its simple version, it holds in its weak form. Coupled with the above finding this means that wherever the Fisher relation holds, it holds in its weak form. There is no country in our sample for which the hypothesis holds in its strong form. However, this may be due to the fact that because of data limitation we had to neglect taxes on interest income.
Secondly, in those developing countries where the Fisher hypothesis holds in its augmented form, the coefficient of the inflation risk is positive and significant in 18 and negative and significant in seven developing countries.

\section{References}

Berument, H. (1999) The impact of inflation uncertainty on interest rates in the UK, Scottish Journal of Political Economy, 46, 207-18.

Berument, H. and Dincer, N. (2005) Inflation and inflation uncertainty in the G-7 countries, Physica A, 348, 371-9.

Berument, H. and Jelassi, M. (2002) Fisher hypothesis: a multi-country analysis, Applied Economics, 34, $1645-55$.

Berument, H., Kilinc, Z. and Ozlale, U. (2005) The missing link between inflation uncertainty and interest rates, Scottish Journal of Political Economy, 52, 222-41.

Bollerslev, T. (1986) Generalized autoregressive conditional heteroskedasticity, Journal of Econometrics, 31, 307-27.

Bomberger, T. (1996) Disagreement as a measure of uncertainty, Journal of Money, Credit and Banking, 28, 381-92.

Chan, L. K. C. (1994) Consumption, inflation risk, and real interest rates: an empirical analysis, Journal of Business, 67, 69-96.

Crowder, W. J. and Hoffman, D. L. (1996) The long-run relationship between nominal interest rates and inflation: the Fisher equation revisited, Journal of Money, Credit and Banking, 28, 102-18.

Davis, G. and Kanogo, B. (1996) On measuring the effect of inflation uncertainty on real GNP growth, Oxford Economic Papers, 48, 163-75.

Darby, M. (1975) The financial and tax effects of monetary policy on interest rates, Economic Inquiry, 13, 266-76.

Dutt, S. D. and Ghosh, D. (1995) The Fisher hypothesis: examining the Canadian experience, Applied Economics, 27, 1025-30.

Engle, R. (1982) Autoregressive conditional heteroskedasticity with estimates of the variance of United Kingdom inflation, Econometrica, 50, 987-1007.

Evans, M. D. D. and Levis, K. K. (1995) Do expected shifts in inflation affect estimates of the long-run Fisher relation?, Journal of Finance, 50, 225-53.

Fama, E. (1975) Short term interest rates as predictor of inflation, American Economic Review, 65, 269-82.

Fama, E. and Gibbons, M. (1982) Inflation, real returns and capital investment, Journal of Monetary Economics, 9, 297-323.

Fama, E. and Schwart, G. (1977) Asset returns and inflation, Journal of Financial Economics, 5, 115-46.

Fisher, I. (1907) The Rate of Interest, Macmillan, New York.

Grier, K. and Perry, M. J. (1998) On inflation and inflation uncertainty in the G7 countries, Journal of International Money and Finance, 17, 671-89.

Hafer, R. W. (1986) Inflation uncertainty and a test of the Friedman hypothesis, Journal of Macroeconomics, $\mathbf{8}$, $365-72$. 
Hahn, F. H. (1970) Savings and uncertainty, Review of Economic Studies, 37, 21-4.

Hamilton, J. D. (1994) Time Series Analysis, Princeton University Press, Princeton, NJ.

Hsing, Y. (1997) The Fisher hypothesis revisited: new evidence, Applied Economics, 29, 1055-9.

Jansen, D. W. and Cosimona, T. F. (1988) Estimates of the variance of US inflation based upon the ARCH model: comment, Journal of Money, Credit and Banking, 20, 409-21, Part 1.

Johnson, D. R. (2002) The effect of inflation targeting on the behavior of expected inflation: evidence from an 11 country panel, Journal of Monetary Economics, 49, 1521-38.

Juster, F. T. and Taylor, D. (1975) Towards a theory of saving behaviour, American Economic Review, 65, 203-9.

Juster, F. T. and Wachtel, P. (1972a) Inflation and the consumer, Brookings Papers, 1, 71-114.

Juster, F. T. and Wachtel, P. (1972b) A note on inflation and the saving rate, Brookings Papers, 3, 765-78.

Lee, J. L., Clark, C. and Ahn, S. K. (1998) Long- and shortrun Fisher effects: new tests and new results, Applied Economics, 30, 113-24.
Mankiw, N. G., Reis, R. and Wolfers, J. (2003) Disagreement about inflation expectations, NBER Working Paper 9796.

Markowitz, H. (1952) Portfolio selection, Journal of Finance, 7, 77-91.

Mishkin, F. S. (1981) The real interest rate: an empirical investigation, Carnegie-Rochester Conference Series on Public Policy, 15, 151-200.

Mishkin, F. S. (1992) Is the Fisher effect for real?, Journal of Monetary Economics, 30, 195-215.

Olekalns, N. (1996) Further evidence on the Fisher effect, Applied Economics, 28, 851-6.

Rosanna, R. J. and Seater, J. J. (1995) Temporal aggregation and economic time series, Journal of Business and Economic Statistics, 13, 441-51.

Sheehan, R. G. (1996) Adaptive versus rational expectations and the Fisher effect, Applied Economics, 28, 1-11.

Tobin, J. (1965) Money and economic growth, Econometrica, 33, 671-84.

Tolvi, J. (1999) Small sample properties of a joint ARCHbilinearity test, University of Turku, Department of Economics, Research Report No. 84.

Tolvi, J. (2000) The effects of outliers on two nonlinearity tests, Communications in Statistics-Simulation and Computation, 29, 897-918. 